\title{
USING BOOKS IN ADDRESSING THE SOCIO- EMOTIONAL PROBLEMS OF CHILDREN WITH HEARING IMPAIRMENT
}

\author{
Rowena V. De La Cruz ${ }^{1 *}$ and Maria Corazon Colendrino ${ }^{1}$ \\ ${ }^{1}$ De La Salle University, Philippines
}

\begin{abstract}
The lack of communication skills in children with hearing impairment poses difficulties in the detection and management of their socio-emotional issues. Unaddressed, these could negatively impact school performance. In search for possible interventions, an exploratory research used mixed methods to look into the use of books and read aloud activities using sign language. It sought to establish: 1. How the teachers select books for relevance, conduct the reading sessions, elicit responses from the hearing impaired children and process their issues; and 2. How the children with hearing impairment benefit from such activity. Of thirty (30) teachers surveyed, six (6) had previous training in therapeutic interventions and were using book therapy at the time of the study. Critical purposive sampling, the teachers were selected as respondents in case studies, along with six (6) hearing impaired children who were experiencing communication, anxiety and self-concept issues. The study employed a triangulation of the following methods: in-depth interviews and nonparticipant class observation of read aloud activities. Findings suggests that: 1. Reading material selection takes into consideration hearing impairment and the presenting socio-emotional issues of the students; 2. Books are low cost effective therapy tool, but locally produced ones depicting Filipino characters are hard to come by; 3 . Read aloud activities are enhanced by the use of art activity and role playing, allowing the students to express themselves in variety of ways; and 4. Discussion allows the students to express how they relate with the characters, understand their issues better and works towards problem solving. The writing of books depicting Filipino characters and the conduct of more researches on the topic are recommended.
\end{abstract}

Keywords: Socio-Emotional Problems, Read Aloud, Children with Hearing Impairment

\section{Introduction}

Children with hearing impairment (CHI) experience issues that have the potential to negatively impact their social and emotional well-being and performance in school. Problems in communication, social development (e.g. adjusting to school, making friends, working together), low self-esteem or self-concept and coping with depression, fear and anxiety are among the many circumstances that can interfere with hearing impaired students' healthy functioning and learning (Rozalski, Stewart \& Miller, 2010). Books are typically an abundant resource in schools, and can be inexpensively obtained from public libraries and local book stores, making the use of book through read aloud a practical method to address students' social and emotional needs.

Reading aloud is an important and valuable student activity within the classroom. Conventions of print can also be taught and reinforced through read aloud (Trelease, 2006). In addition, comprehension skills can be honed through read aloud (Lane \& Wright, 2007). Dialogic read aloud can help develop language skills (Flynn, 2011). As Gavigan \& Kurtts (2011) suggested that interactive read aloud can not only build vocabulary and comprehension skills but also build a sense of community and socio-emotional development in the classroom through the co-construction of knowledge between teachers to students and student to student. They continue that this application of reading aloud with a purpose outside the realm of reading and literacy can be defined an approach that uses books to effect affective outcomes such as understanding, coping with challenges, and promoting social-emotional growth. And as Lane \& Wright (2007) suggested that read aloud practice in the school be done in a comfortable area, to prepare for the activity by: "a. Select the focus and gather several 
books on the topic; b. Arrange to read the books in order, from simple to more complex; and c. Prepare for the read aloud by pre-reading and marking passages that require more time to think aloud and to invite student discussion. Lastly, during the activity: a. Introduce the subject and tell the students why you selected the book; b. Introduce the book and tell how it fits into the study, and c. After reading aloud, invite students to do a retelling of the text" (p. 670).

Moreover, one of the many benefits of using books is that it requires minimal preparation and can be easily implemented by teachers in the school (Zins \& Elias, 2007). Stories can provide children with a non-threatening and often enjoyable way to deal with difficult circumstances (Goddard, 2011). Thus, books through read aloud provide a cost and time-effective, non-intrusive method for teachers to help guide their students through difficult experiences and promote their healthy development and success.

\section{Methodology}

This study employs the use of mixed method-case study design methodology. The case study design was used for this study to emphasize the detailed analysis of the event or conditions and their relationship.

Case Studies combine a variety of data collection methods such as interviews, questionnaires and observation. Data which are collected from interviews and from questionnaires like qualitative; such as words or quantitative, such as numbers or both are generated.

A mixed methods research design, which employs characteristics of quantitative and qualitative methods, was also chosen for this study to reach conclusions through the most suitable process of procedures and established principles by collecting and analyzing qualitative and quantitative data.

\section{Results and Discussions}

Communication issues are the least that hearing impairment can bring to school-age children. Beneath the tip of the iceberg are socio-emotional issues that they can acquire because of the inability or lack of skills to communicate. But the disabling condition itself poses difficulties in the detection and management of their socio-emotional issues. Without the ability to express themselves via spoken words, their mentors will never know if they need help or not. Unaddressed, these could negatively impact social development and performance in school.

Socio-emotional issues can greatly limit the hearing impaired children's chances at making friends and socializing with the other members of the school community as a whole, alienating them in the process. The local and global initiative for inclusion behooves teachers to look for ways to address the socio-emotional issues in children with hearing impairment before they escalate to behavior disorder.

Consequently, this chapter presents the results of the case studies on teachers and children with hearing impairment. These answer the two research questions: 1. How do teachers use books in addressing the socioemotional problem of children with hearing impairment?;and 2. How do children with hearing impairment benefit from the read aloud activities in class?

The six case studies on teachers are simply coded as Teacher 1 to Teacher 6. Likewise, the case studies on children with hearing impairment are simply coded as Pupil 1 to Pupil 6. These present the data collected through in-depth interview and non-participant class observations of read-aloud activities. Cross-case analyses are presented to answer the research questions. 


\section{Individual Case Report}

\section{Research Question 1: How do teachers use books in addressing the socio-emotional problem of children with hearing impairment?}

Teacher 1: Uses picture story books, film and/or videos to address these socio-emotional problems, as they have proven to be effective in dealing with communication issues, depression, fear, and anxiety. "theuse of books through read-aloud helps students understand what they are experiencing, overcome their fear or anxiety and helps find solution to the present situation/issues they have".

Teacher 2:Considers communication issues, depression and social development when choosing her materials. "The books they read make or helps the deaf child with the same problem understand that they are not the only one experiencing the same problem. The picture story book in a way help or answered the problem".

Teacher 3: Book through read aloud can help address specific issues being faced by a hearing impaired child: "It is an alternate way to help a deaf child deal with the problem or issues he/she is presently encountering".

Teacher 4: Respondents' revelation on the use of book in addressing socio-emotional problem of a child with hearing impairment was that: "The use of book(s) is a natural way to teach and support children. Stories allow children to understand that other child faces the same challenges in their life". Books "serves as a role model on how to handle problem and develop their character".

Teacher 5: As the respondent suggested, the books were helpful because: "Students can relate themselves with the characters".

Teacher 6: The respondent agrees that the use of books through read aloud, especially to a hearing impaired student with socio-emotional problem can be an instructional tool a teacher can use to help children experiencing socio-emotional problem cope with their diverse needs and life's challenges. "It can easily explain the problem", that books "can relate to what the child is going through and that there is a way out".

\section{Sub Question Research Question 1:1a. What are the Perception of Teachers about the Use of Books Through Read Aloud?}

Teacher 1:Students are able to use empathic skills torelate the stories to themselves and to others, and to recognize when their experience or story is different or the same with the character(s) of the story.

Teacher 2: Teacher 2 considered the use of books through read aloud as: "Absolutely vital ... a cheap alternative to help student understand their problem and how they can handle it".

Teacher 3: Storytelling help such children cope with issues, "books normalizes their thoughts, by letting them know that they are others like them with the same problem", she continued that after each read aloud activity "it starts up a conversation, they can sayin the form of the character, how or what they feel inside".

Teacher 4: Respondent states that books are a "natural way to teach and to support children" and "stories allow students to understand that other people face the same challenges in their lives and books offer role modeling on how to handle problems and develop their character".

Teacher 5: The respondent shared the following perception about the use of books through read aloud in addressing the socio-emotional problem was: "It let students know that they are not alone, books guides them and is a cheap way to help a child with his/her problem as well as educate them". 
Teacher 6: The respondents mentioned that books was a useful tool for helping children to connect with others. As the respondent said that: "Children can easily make the connection to oneself and their community through a book".

\section{Sub Question Research Question 1:1b. What are the Challenges in Using Books Through Read Aloud?}

Teacher 1:A deaf heroin portrayed by a Filipino in a story is very hard to find.

Teacher 2: The respondent revealed that the high cost of picture book and the absence of localized book were also the two challenges she has encountered in using book to help address socio-emotional issues of hearing impaired students. "It would be nice to have Filipino child with the same problem to address ... it makes it very realistic".

Teacher 3: The respondent shares the sentiment of other respondents on the lack of localized books that can be used in therapeutic intervention for children with hearing impairment. "Picture books are mostly in foreign setting, especially those that have a deaf child/children as the main character".

Teacher 4: Unavailability of localized book and books being expensive were the two challenges the respondent mentioned, as she continued that it would make it very realistic if the characters were Filipinos.

Teacher 5: A significant barrier encountered by the respondent was the unavailability of localized book. As experienced during the observation, when the context of what was being read was closely similar to the reader, they would be able to connect best because they could relate personally to the characters.

Teacher 6: The unavailability of localized book is the barrier that the respondent had encountered with the use of books. If the books were in Filipino characters, it would have been easier for the respondent to relate scenes, characters and lessons/values to their lives.

\section{Sub Question Research Question 1:1c. What are the Teachers Personal Choice of Books to use during Read} Aloud?

Teacher 1:Story picture books the respondent selected as her personal choice is "Alan \& the Baron" by Ron Hamilton. "I like Alan and the Baron ... the book make students make use of what they have."

Teacher 2: Even in the absence of reading materials in localized setting, her choice of the "I am Deaf and It's Okay" by Lorraine Aselthine, proved effective in addressing her students' issues. She found right fit even if the characters were not Filipino children.

Teacher 3: Respondent cited "Rosa's Parrot" by Ian Wahl. It is a book about forgiveness, building friendship and understanding and forgiveness.

Teacher 4: The book "A Very Special Egg" by Patricia Dyreson, is Teacher 4 personal choice, it is a story about two different boys (one deaf and one hearing), and who together discovered the meaning of life.

Teacher 5: Respondents cited "Secret Signs along the Underground Railroad" by Anita Riggio, which is all about bravery and courage.

Teacher 6: Respondents favored the book "A Very Special Egg" by Patricia Dyreson, this book for her helps the child to accept him/herself as they are.

Research Question 2: How do children with hearing impairment benefit from the read aloud activities in class? 
Pupil 1:The respondents' realization after the read aloud activity was finished revealed that she had learned there are others like her and she is just the same as everyone else.

Pupil 2:The respondent mentioned it helped her and realized that she is not at all different and to accept herself as she is.

Pupil 3: After the read aloud activity, the realization of the respondent was, what she experiences, others experiences it too.

Pupil 4: What he had realized from the activity, was that he was not alone in the situation he is in, he realized that there are others like him as the story narrates.

Pupil 5:He feels that the pictures, interacts with him and at the end of the read aloud activities the respondent realized that had to be brave always

Pupil 6: After the read aloud activity, the respondent realized that she always hadto have courage or be courageous at all times.

\section{Cross Case}

Research Question1: How do teachers use books in addressing the socio-emotional problem of children with hearing impairment?

This section describes the cross-case analysis of the study or the similarity and difference of the responses of each of the SPED teacher respondent.

Similarities - their unanimous response for Q1 that most often they use picture books to hearing impaired children who have socio emotional problem is consistent with Betzalel \& Shechtman's (2010) hypothesis that fictional books "speak to the children's imagination and increase their attention and interest," (p. 436). The respondents also included other types of books such as video or film stories in teaching children with hearing impairment.

When asked how difficult it was to locate books that portray children with hearing impairment having socioemotional problem under Q3a, 100\% responded that it was somewhat difficult to find books portraying children with hearing impairment having socio-emotional problem. This is congruent with studies indicating that the representation of socio-emotional problem in children's books has become more inequitable over time (Hermann-Wilmarth, 2007).

Q4 asked the respondents whether they use books through read aloud with individuals, groups, or both. All of them indicated that they used books through read aloud with groups. Research has demonstrated that the most effective read-aloud are done in group, in which children are actively involved asking and answering questions and making predictions rather than passively listening (Lane \& Wright, 2007). In Q5 respondents were asked what activities, if any, they use in conjunction with books. Multiple responses were permitted. Results showed discussion, art, role-play or drama activities and writing were the most common activities used with books through read aloud. This result lends support for the use of accompanying activities with books in addressing the socio-emotional problems. It is also consistent with previous studies evaluating book-related interventions with hearing impaired children; some form of beneficial discussion or activity appears to be a common component in many of these studies (Betzalel \& Shechtman, 2010).

For Q6, all six (6) respondents answered that they often use variety of methods for selecting books for the read aloud activity with hearing impaired children having socio-emotional problem. This method include 
Independent Research or Read the Book Myself or Recommended by Peers or from Library Resources. This finding corroborates findings from Pehrsson \& McMillen's (2010), in which respondents reported reading the book themselves and using peer recommendations as primary methods for selecting books. The authors continued that they were surprised to find that participants reported using library resources for finding books. They referred to librarians as "undiscovered therapeutic allies," (p. 422) due to their specialized knowledge about literature.

Lastly, respondents were next asked Q9, whether they agreed, disagreed, or felt unsure in response to the statement books through read aloud help address the socio-emotional problem of children with hearing impairment. All respondent indicated that they agreed with the statement. This result is promising as it indicates that SPED Teachers see a connection between literature and broader, macro-level issues about socio-emotional, a stance that is consistent with teaching values (Betzalel \& Shechtman, 2010).

Differences - When Q2 asked about the approximate age group of children with hearing impairment the respondents cater to, even though their students belong to the same group age, two from the six respondents handle a different grade level. The respondents were then asked on Q3, how often they attempt to use books through read aloud that portray characters representing their children socio-emotional problems. Five respondents answered "most of the time", while Teacher 4 answered that she "always" use books through read aloud portraying their children's socio-emotional problems. This finding lends support to the notion that SPED Teachers are taking issues of their children socio-emotional problems into consideration in their selection of books for children (Pehrsson \& McMillen, 2010).

For Q7, with which socio-emotional problem have you used books through read aloud, multiple responses were again permitted. Five respondents answered that they used books through read aloud to address problems with "communication", "depression, fear and anxiety", and "social development" while Teacher 1 used it to help with "communication" and "depression, fear and anxiety" problems. These problems extend beyond those mentioned in Perhsson \& McMillen's (2010) as some of the problems most applicable for children with hearing impairment and are likely to differ from those faced by adult. None the less, all of the respondents agreed that they found books through read aloud to be an effective strategy to use for all the socio-emotional problems mentioned. This finding echoes previous studies suggesting that books through read aloud is a widely used beneficial tool (Pehrsson \& McMillen, 2010).

In response to Q8 to list some titles of books that you find most useful for addressing these problems during reading, the following books were frequently cited by five respondents: "A Very Special Egg" by Patricia Dyreson and "I am Deaf and It's Okay" by Lorraine Aselthine, and "Rosa's Parrot" by Ian Wahl. Only Teacher 2 gave a different title: "Dina, the Deaf Dinosaur" by Carol Addabbo “Alan \& the Baron” by Ron Hamilton, and "Secret Signs along the Underground Railroad" by Anita Riggio. In addition to, the results of Q10 which was have you received formal education or training on the use of books through read aloud in addressing the socioemotional problem of children with hearing impairment, shows that they are all graduate students, five (5) of them had graduated their Masters in Special Education while Teacher 3 obtained their MA academic completion. In addition, all of the respondents indicated that they received professional training on the use books through read aloud in addressing the socio-emotional problem of children with hearing impairment, Teacher 1, Teacher 2, Teacher 3, Teacher 6 was trained with book and play therapy while Teacher 4 and Teacher 5 received trainings for book, arts and play therapy. This result makes sense in light of Pehrsson \& McMillen's (2010) study, which found standardized programs for preparing professionals to use books to help address issues or problem faced by children with disabilities.

To sum up the cross-case analysis in answering research question no. 1, as to how do teachers use books in addressing the socio-emotional problem of children with hearing impairment, what have been observed and collected by the researcher clearly shows that books through read aloud have an overall beneficial effect on the 
well-being of individuals, including children with hearing impairment experiencing socio-emotional problem(s). In summary, the benefits of using books through read aloud include the following: teachers can help their class through difficult situations; enable children with hearing impairment to surpass their own challenges; and teach them to consider all viewpoints, respect differences, and become more self-aware.

\section{Sub Question Research Question1 - 1a. What are the Perception of Teachers about the Use of Books Through Read Aloud?}

All of the respondents' comments expressing positive feelings about using books in therapy, as well as comments referencing a variety of uses for books. Most of the respondents reported that books are one of their most favored interventions with hearing impaired children, referring to them as "absolutely vital," and one of the most effective tools. They also identified a variety of therapeutic reasons to use books with hearing impaired children, including: starting a conversation about a particular issue, learning complex ideas, providing permission to talk about difficult subjects, helping hearing impaired children know they are not alone, and by normalizing thoughts. This finding echoes Smolkin and Young's (2011) description of books as "self-affirming mirrors" or "windows into other lives" (p. 217).

\section{Sub Question Research Question1 - 1b. What are the Challenges in Using Books Through Read Aloud?}

The first barrier cited by most of the respondents is the unavailability of localized book. As one of these respondents explained, it is very hard to find book with a Filipino as the main character or the setting is done within the Philippines. It is important for their students to easily relate within the story. This stance is consistent with research suggesting that the use of books as an intervention using elements of a child's culture may be more effective than interventions without cultural specificity (Constantino, Malgady \& Rogler., 1994).

Books being expensive is the second challenges cited by all of the respondents. Story picture books being expensive limits the collection of books available for use as an intervention.

\section{Sub Question Research Question1 - 1c. What are the Teachers Personal Choice of Books to use during Read Aloud?}

Respondents cited several book titles as their personal choice to use with hearing impaired children suffering from socio-emotional problem. The books were: "A Very Special Egg” by Patricia Dyreson, a story about two different boys (one deaf and one hearing), who together discovered the meaning of life, This story picture book address socio-emotional problem about communication, self-concept and depression, fear and anxiety. The story book "I am Deaf and It's Okay" by Lorraine Aselthine. caters to the entire socio-emotional problem discussed above and "Rosa's Parrot" by Ian Wahl is a picture book about friendship, forgiveness and being a voice even if no one can hear you. Rosa's Parrot is a very good story picture book to read if you are addressing problems about social development, communication, depression, fear and anxiety and self-esteem. Story picture books that were also selected are "Alan \& the Baron" by Ron Hamilton is about a deaf child who is being taught by a hearing child to uses not just sign language to communicate but this other senses and gestures, both of this story picture books according to two respondents are very good in addressing problems with communication, depression, fear and anxiety, self-concept and social development. "Secret Signs along the Underground Railroad" by Anita Riggio, is all about bravery and courage, this can address issues about depression, fear and anxiety, self-esteem and self-concept. and "Best Buddies and the Fruit of the Spirit" by Betty Rushford is about teaching deaf children the importance of accepting who they are as well as accepting others as they are, this story picture book address issues about self-concept, and self-esteem.

Research Question 2: How do children with hearing impairment benefit from the read aloud activities in class? 
The cross-case study or the similarity and difference of the responses of the children with hearing impairment respondent are as follows.

Similarities -All of the respondents have a unanimous response on CHI Q1 about what they like about the read aloud activity was the pictures or the illustrations on the book being read. On the other hand, they have different reason as to why they like the pictures or illustrations. They mentioned that they like the pictures/illustrations on the book because the pictures on the book feel like it is "talking (and/or interacting) with them". Pictures are important because of how readers interact with them, especially during the read-aloud experience of children with hearing impairment. It feels like a magic begins when the reader opens up the book (Hargrave \& Sènèchal, 2000).

In answering CHI Q4, all respondents answered "Yes" in response to the question if they would be joining another read aloud activity. On the other hand when it comes to justifying their replies each CHI respondents gave different opinions.

Differences -When the CHI respondents were asked about CHI Q1a about what they dislike about the read aloud activity done in their classroom, their responses have nothing to do with the book they just read but about the activity they have to do in connection with the read aloud exercise, like the discussion and the role-playing activity. Pupil 2 and Pupil 6 do not like the "discussion activity" because she "feel(s) (that I will) get laugh at" and "(my) opinion (may be) wrong", the remaining respondents dislike the "role-playing activity" because they are too shy to act out or portray a role.

When all of the respondents were asked after each read aloud activity in their respective classrooms about what they have learned or realized from the story picture book, they have varied responses. For Pupils 1, 2, 3 and 4, they are now certain that they no longer need to feel depressed or lonely because they are "not alone" or "that (there are)others like me" who are experiencing the same problems or issues from the story picture book. They realized that others have the same difficulties in dealing with issues. For Pupil 5 and Pupil 6, they realized that they should always have courage to face all the difficulties they are experiencing, as may be gleamed from the following responses: "I (have to be) brave" or "find courage" to face all the fears that will come their way.

For CHI Q3, their selections include: A Very Special Egg by Patricia Dyreson, for Pupil 1and Pupil 5. From their point of view they choose this book because it shows to "not (be) afraid (to) face problem" and "(I can be the) same (as) others". Pupil 2 preferred, I am Deaf and It's Okay by Lorraine Aselthine, for this book helps “(to) accept me (myself as I am) as me".Rosa's Parrot by Ian Wahl, was selected by Pupil 4, because for him the book showed that you can be the "voice (of) other's (even if you) cannot speak". For Pupil 6 it was the Secret Signs along the Underground Railroad by Anita. This book helped her find courage and bravery. Lastly, Pupil 3 mention two books to be her favorite: I am Deaf and It's Okay, because it helped her accept herself and Secret Signs along the Underground Railroad, for this book made her believe in what she has and can do.

Finally, answering CHI Q4 they unanimously agreed that they will be joining another read aloud activity in their classroom, but have given different reasons as to why they will be joining. Pupils 2, 3 and 4 stated that they will join because after the read aloud activity it made them realize that they do not have to worry and everything will turn out fine at the end. Pupil 1 reasoned that the read aloud activity made her realize that she can speak even if she does not have a voice, by means of facial expressions and gestures, For Pupil 5, after the read aloud activity it made him realize that talking about what they are experiencing made the problem easier to handle, as for Pupils 6, after each activity, she realized that the story made her fell less alone.

Clearly, responding to research question no. 2, for children with hearing impairment experiencing socioemotional issues, the use of books through read aloud helped them deal with specific situations and strengthen their ability to consider various points of view. 


\section{Conclusion}

This research identified that the results of the study provided an understanding on: First, To answer the first research question, teachers in this study used books through read aloud not as an alternate but as a channel for discussion. They identified and discussed the problem by selecting books appropriate for their students' socioemotional problems. Through the read aloud activity, hearing impaired children experiencing socio-emotional problem were encouraged to examine solutions from the book they read and by means of the activities in conjunction with the books teachers can observe and discuss whether the solution to the problem was successful. It encouraged children with hearing impairment to think about possible solutions. And when faced with a difficult situation, teachers look for a book to help explain, to provide a conversation-starter, or to fill in the gaps in their own understanding so as to better address the situation at hand.

In response to the second research question of this study, children with hearing impairment benefit from books through read aloud by assisting them in overcoming problems through having them read stories about characters who have successfully resolved a dilemma similar to their own. Identification with a book through read aloud can foster thought and possible resolution to socio-emotional problems such as communication, self-esteem, self-concept, depression, fear, anxiety and social development. If children with hearing impairment become emotionally involved with literary characters, they are enabled to verbalize, act out, or draw pictures describing their innermost thoughts.

\section{Recommendation}

For other researchers who will conduct the same study, the researcher suggests adding more respondents to more adeptly determine the way teachers use book to address the prevailing socio-emotional problems of children with hearing impairment and what more can these children benefit from using book through read aloud activities done in their classroom.

And for Filipino picture story book author(s) and publisher(s), to create, illustrate and write a book that is closely related to socio-emotional difficulties experienced by Filipino children with or without disabilities.

\section{Acknowledgment}

I wish to express a sincere gratitude to the teachers and children with hearing impairment who so graciously agreed to participate in my study. In the course of gathering this material, interviewing the respondents, and collecting the data, I had invaluable assistance from them who volunteered to share with me their experiences and/or perceptions. Without them, the completion of this study would not have been possible. I thoroughly enjoyed interviewing each one of them and learned so much from their "experiences and/or perceptions" that I can share with all of you and with my own family in the years that follow. Their remarkable source of energy kept me motivated and smiling throughout this process.

I am grateful for the love, encouragement, and tolerance of Elmer B. Enriquez, the man who has made all the difference in my life. Without his patience and sacrifice, I could not have completed this paper. A special word of thanks also goes to my family for their continuous support, encouragement and for never giving up ... I love you, Daddy and Mommy.

\section{References}

Betzalel, N. and Schechtman, Z. (2010). Bibliotherapy treatment for children with adjustment difficulties: A comparison of affective and cognitive bibliotherapy. Journal of Creativity in Mental Health, 5, 426-439. doi:10.1080/15401383.2010.527816 
Constantino, G., Malgady, R.G., and Rogler, L.H. (1994). Storytelling through pictures: Culturally sensitive psychotherapy for Hispanic children and adolescents. Journal of Clinical Child Psychology, 23(1), 1320. doi:10.1207/s15374424jccp2301_3

Flynn, K. S. (2011). Developing children's oral language skills through dialogic reading: Guidelines for implementation. Teaching Exceptional Children, 44(2), 8-16.

Gavigan, K. W. and Kurtts, S. (2011). Using children's and young adult literature in teaching acceptance and understanding of individual differences. The Delta Kappa Gamma Bulletin, Winter, 11-16. Retrieved from http://www.dkg.org

Goddard, A. (2011). Children's books for use in bibliotherapy. Journal of Pediatric Health Care,25, 57-61. doi: 10.1016/j.pedhc.2010.08.006

Hargrave, A., and Sénéchal, M. (2000). A book reading intervention with preschool children who have limited vocabularies: The benefits of regular reading and dialogic reading. Early Childhood Research Quarterly. Special Issue: Evaluating, interpreting, and debating early interventions: The case of the comprehensive child development program, 15, 75-90. Retrieved from http://www.journals.elsevier.com/early-childhood-researchquarterly/

Hermann-Wilmarth, J.M. (2007). Full inclusion: Understanding the role of gay and lesbian texts and films in teacher education classrooms. Language Arts, 84, 347- 356.

Lane, H. B. and Wright, T. L. (2007). Maximizing the effectiveness of read aloud. The Reading Teacher, 60(7), 668-675. Retrieved from http://www.reading.org

Pehrsson, D. and McMillen, P. (2010). A national survey of bibliotherapy preparation and practice of professional counselors. Journal of Creativity in Mental Health, 5, 412- 425.

doi: 10.1080/15401383.2010.527807

Rozalski, M., Stewart, A., and Miller, J. (2010). Bibliotherapy: Helping children cope with life's challenges. Kappa Delta Pi Record, 47(1), 33-37.

Smolkin, L.B. and Young, C.A. (2011). Missing mirrors, missing windows: Children'sliterature textbooks and LGBT topics. Language Arts, 88(3), 217-225.

Trelease, J. (2006). The new read-aloud handbook. New York: Penguin.

Zins, J., and Elias, M. (2007). Social and emotional learning: Promoting the development of all students. Journal of Educational \& Psychological Consultation, 17(2/3), p233-255. 